
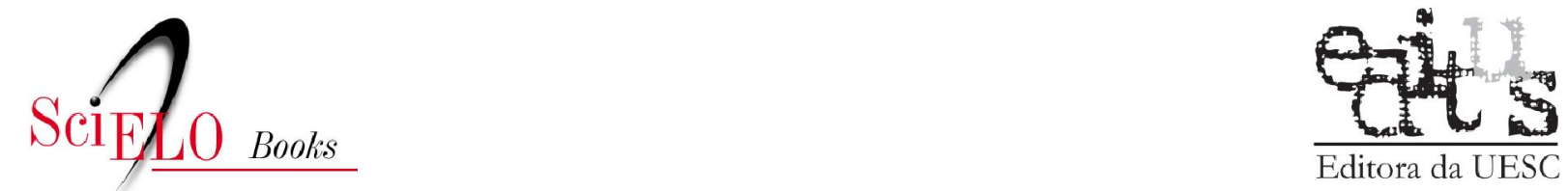

Editora da UESC

\title{
8 Pontos básicos para desenvolvimento de projetos de restauração ecológica
}

\author{
Danilo Sette de Almeida
}

SciELO Books / SciELO Livros / SciELO Libros

ALMEIDA, DS. Pontos básicos para desenvolvimento de projetos de restauração ecológica. In: Recuperação ambiental da Mata Atlântica [online].3rd ed. rev. and enl. Ilhéus, BA: Editus, 2016, pp.

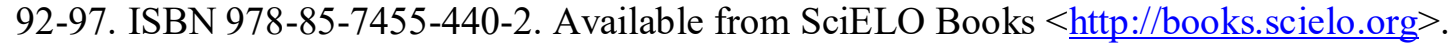

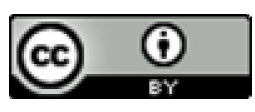

All the contents of this work, except where otherwise noted, is licensed under a Creative Commons Attribution $\underline{4.0 \text { International license. }}$

Todo o conteúdo deste trabalho, exceto quando houver ressalva, é publicado sob a licença Creative Commons Atribição 4.0.

Todo el contenido de esta obra, excepto donde se indique lo contrario, está bajo licencia de la licencia Creative Commons Reconocimento 4.0 . 


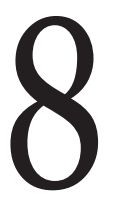

PONTOS BÁSICOS PARA DESENVOLVIMENTO DE PROJETOS DE RESTAURAÇÃO ECOLÓGICA 


\title{
8.1 Seleção de espécies
}

\begin{abstract}
diversidade de espécies utilizadas em projetos de restauração ecológica tem sido um dos pontos bem debatidos ulti1 mamente, torna-se muito importante termos embasamento científico para definição das espécies a serem utilizadas. Informações básicas, provenientes de estudos florísticos e fitossociológicos de ecossistemas e ambientes similares, são fundamentais para explorar e dar consistência a projetos de restauração ecológicos. Número mínimo de espécies a serem utilizadas já é exigido como podemos observar em legislação pertinente do estado de São Paulo, onde a Secretaria de Meio Ambiente, através da Resolução SMA 8, de 7-3-2007, determina que
\end{abstract}

\begin{abstract}
sempre será plantado um mínimo de 80 espécies nativas diferentes por hectare, respeitando critérios de divisão por classe de sucessão e condições específicas do local escolhido, visando restaurar a vegetação nativa da área ao mais próximo possível de sua condição original.
\end{abstract}

Também Martins (2012) relata esta questão da diversidade na restauração ecológica e afirma que

[...] fica evidente a importância do ecossistema de referência no planejamento da restauração ecológica. A restauração deve, portanto, ser planejada e avaliada com base na diversidade natural do tipo de ecossistema que se pretende restaurar.

Um dos pontos básicos para o sucesso do processo de recuperação de áreas degradadas é a correta seleção de espécies. A seleção de espécies é feita em função das condições climáticas, relevo, solos e biodiversidade local (GALVÃO; MEDEIROS, 2002).

Considerando o atual nível de conhecimento biológico de ecossistemas e sucessão, e a grande interação existente entre flora e fauna em áreas de floresta tropical, como a floresta atlântica, em recuperação ambiental, devemos somente utilizar espécies típicas dos ambientes específicos que estão sendo recuperados. Para isso é necessário um bom conhecimento do processo sucessional da região e da autoecologia das espécies a serem trabalhadas. O nível de detalhamento dos levantamentos de flora e fauna e o conhecimento das espécies vão variar em função da escala - tamanho da área que temos de reabilitar. 
Para a seleção de espécies a serem utilizadas em trabalhos de recuperação ambiental, podemos usar métodos diferenciados. A melhor maneira de aproximar da composição e da estrutura original do ecossistema degradado é realizar o processo de seleção de espécies, baseado no conhecimento detalhado da composição florística e fitossociológica de ambientes similares, ao que se deseja recuperar. Neste caso, além da composição e estrutura dos diferentes estágios sucessionais da vegetação (inicial, médio e avançado), visando conhecer e dominar o processo sucessional do ecossistema específico a ser recuperado. $\mathrm{O}$ conhecimento da flora e da estrutura de áreas de floresta primária (estágio clímax de sucessão) é referência básica do ponto onde queremos chegar (estrutura e composição final do trabalho de restauração).

Importantes referências para a seleção de espécies são obtidas em trabalhos de recuperação ambiental em regiões com condições similares àquelas que estamos trabalhando, como também observações do desenvolvimento de espécies em arboretos e plantios experimentais e observações em áreas degradadas em início de regeneração natural, vizinhas ao local que queremos recuperar.

A utilização de conceitos, como o de classificação de grupos ecofisiológicos de espécies (vide capítulo 5), facilita o entendimento do processo de sucessão e consequentemente a seleção de espécies. Dentre os grupos ecofisiológicos de espécies a serem utilizados, o grupo de espécies pioneiras se destaca principalmente para áreas mais degradadas. Quando nos referimos à utilização de espécies pioneiras, é importante não restringirmos a espécies pioneiras arbóreas, mas contemplarmos outros grupos de espécies como gramíneas e arbustivas, que conferem uma rápida proteção aos solos degradados, principalmente em áreas totalmente desprovidas de vegetação.

Com referência ao número de espécies a serem utilizadas, lembramos de que no processo natural a diversidade de espécies vai aumentando gradativamente, portanto, quando se conhece bem a sequência sucessional do ecossistema que está sendo recuperado, é possível utilizar um menor número de espécies na fase inicial (preferencialmente pioneiras e secundárias iniciais) e, posteriormente, enriquecer com espécies secundárias tardias e clímax, acelerando o processo natural de sucessão.

Vários autores citam critérios para seleção de espécies vegetais para fins de revegetação. A Secretaria do Meio Ambiente de São Paulo (1990) e Reis et al. (1999) relacionam uma série de critérios para seleção de espécies, ou seja: 
a. ocorrência natural na região;

b. ter caráter pioneiro, apresentando rápido crescimento, recobrindo rapidamente o solo e paralisando os processos erosivos;

c. alto potencial de dispersão da espécie;

d. rusticidade, apresentando bom desenvolvimento em solos com baixo teor de matéria orgânica e fertilidade;

e. produzir alimento para a fauna regional (zoocórica);

f. facilidade de propagação e obtenção de mudas;

g. apresentar grande densidade foliar;

h. apresentar grande potencial de reciclar nutrientes, fertilizando o solo e incorporando matéria orgânica neste substrato.

Portanto, na recuperação de áreas degradadas, necessitamos de espécies de crescimento rápido, que acelere o recobrimento do solo, com sistemas radiculares profundos que tragam nutrientes de camadas mais profundas do solo para a superfície, promovendo a ciclagem de nutrientes e acumulando matéria orgânica nas camadas superiores do solo (formação da manta orgânica), criando condições para o desenvolvimento de outras espécies. Do mesmo modo, é considerada como característica desejável, um bom formato de copa, com parte aérea bem desenvolvida lateralmente para proteção do solo.

\subsection{Inserção na paisagem, interação com vizinhança}

No início da arte de restauração de ecossistemas, a área destinada à restauração era vista de forma isolada e pontual, sem observar a paisagem circundante à área de intervenção. Com o desenvolvimento da área de Ecologia da Paisagem, iniciamos a aplicação destes conceitos no processo de restauração ecológica, de forma que a área destinada para restauração não é hoje mais vista de forma isolada, mas inserida no contexto da paisagem circundante e regional. A evolução da ciência de planejamento e ecologia da paisagem fornece hoje uma base teórica extremamente importante para a área de restauração, destes estudos originaram os planejamentos de corredores ecológicos, onde, a partir do estudo da paisagem, é definido o melhor "caminho" para interligação de dois fragmentos florestais isolados na paisagem. 
Quando consideramos os novos caminhos da restauração ecológica, e não somente de uma recuperação florestal, mas de uma restauração do ecossistema e ambiente natural, a interligação de áreas isoladas, em que temos populações de flora e fauna isoladas, esta busca da conectividade de fragmentos permite o aumento do fluxo gênico e intercâmbio entre as populações vegetais e animais destes fragmentos florestais isolados. Em função do tamanho e estado de conservação dos fragmentos, a serem interligados, este planejamento de implantação de corredores, interligação de áreas florestais remanescentes, pode ter um grande retorno na restauração destes ambientes.

Em áreas de floresta atlântica, nas quais temos grande fragmentação de habitats, a visão da paisagem torna-se fundamental para o planejamento espacial da restauração ecológica, as estratégias de restauração passam não somente por boas técnicas de plantio, com espécies bem selecionadas e adequadas aos diferentes ambientes, mas também pela visão espacial, onde a área, objeto da restauração, possa se inserir e se conectar na paisagem por fragmentos florestais vizinhos ou adoção da técnica de ampliação ecológica.

\subsection{Princípios da Sucessão Ecológica}

Conforme mencionado anteriormente, o grande aprendizado na área de restauração ecológica nos é dado pela mãe natureza. As observações dos princípios de sucessão são fundamentais para acelerarmos o processo sucessório vegetal e a restauração da área degradada. Hoje, este conceito e a aplicação destes princípios da sucessão ecológica são básicos para restaurar ecossistemas tropicais como a floresta atlântica. A boa observação de campo, anotando as espécies pioneiras presentes na área que se pretende restaurar, assim como a realização de estudos florísticos e fitossociológicos para melhor conhecimento da Sucessão Ecológica, é fundamental para subsidiar o planejamento e o projeto de restauração ecológica.

\subsection{Métodos biológicos de recuperação de áreas degradadas}

A utilização de métodos biológicos na recuperação de áreas degradadas constitui a maneira mais econômica e eficiente de 
recuperação destas áreas. Métodos mecânicos e obras civis representam custos elevados e nem sempre são alternativas eficientes para recuperação de áreas. Neste capítulo, procuramos discutir os métodos biológicos mais utilizados na recuperação de áreas degradadas. Estas técnicas estão sofrendo grandes avanços ultimamente e têm evoluído dia a dia em suas aplicações. Nas últimas décadas, tem crescido o interesse por recuperação de áreas degradadas, e este interesse tem colaborado para o aprimoramento de técnicas visando melhorar e acelerar este processo.

No próximo capítulo, citamos algumas das principais técnicas utilizadas atualmente, enfocando principalmente aspectos práticos, visando facilitar a operacionalidade de implantação. Muitos dos métodos mencionados, nesta parte, podem e devem ser combinados entre si, visando maximizar os benefícios e acelerar ao máximo o processo de recuperação. 